\title{
Ressarcimento ao SUS: aspectos teóricos e práticos na assistência à saúde
}

\author{
Reimbursement to SUS: theoretical and practical aspects in health care
}

Reembolso al SUS: aspectos teóricos y prácticos en salud

Adam Carlos Cruz da Silva ${ }^{1 *}$.

\begin{abstract}
RESUMO
Objetivo: Verificar um breve painel financeiro, a norma vigente e verificar as questões práticas do ressarcimento ao SUS. Métodos: Tratou-se de um estudo quantitativo e original para a análise do ressarcimento ao SUS. A coleta de dados ocorreu no banco de dados da ANS e o repositório do Google acadêmico. Resultados: Segundo informações da ANS foram repassados, na avaliação dos últimos 5 anos mais de 3 bilhões, com um ganho recorde no ano de 2019.Os atendimentos realizados entre os anos de 2015 e 2019 com maiores valores cobrados no grupo de internações são os transplantes de rim, os tratamentos de doenças bacterianas, o tratamento de cirurgias múltiplas etc. Nos atendimentos ambulatoriais de média e alta complexidade destacam-se a hemodiálise, hemodiálise em paciente com sorologia positiva para o HIV e/ou Hepatite B e/ou Hepatite C etc. Recomendações para as auditorias de prontuários em unidades públicas pelos Auditores das OPSs são importantes para a organização do processo. Conclusão: Verificou-se que o ressarcimento ao SUS trouxe mudanças no cenário da assistência à saúde no país, com o aumento no ressarcimento de recursos e práticas a serem aperfeiçoadas.
\end{abstract}

Palavras-chave: Ressarcimento ao SUS, Saúde suplementar, Sistema Único de Saúde.

\begin{abstract}
Objective: To check a brief financial panel, the current rule and to check the practical issues of reimbursement to SUS. Methods: This was a quantitative and original study for analyzing the reimbursement to SUS. Data collection took place in the ANS database and the academic google repository. Results: According to information from the ANS, more than 3 billion were passed on in the evaluation of the last 5 years, with a record gain in 2019. The services performed between the years 2015 and 2019 with higher amounts charged in the hospitalization group are transplants kidney disease, treatments for bacterial diseases, treatment of multiple surgeries, etc. In outpatient care of medium and high complexity, hemodialysis, hemodialysis in a patient with positive serology for HIV and / or Hepatitis B and / or Hepatitis C etc stand out. Recommendations for the auditing of medical records in public units by the PAHO auditors are important for the organization of the process. Conclusion: It was found that the reimbursement to SUS brought changes in the health care scenario in the country, with an increase in the reimbursement of resources and practices to be improved.
\end{abstract}

Keywords: Reimbursement to SUS, Supplementary health, Unified Health System.

\section{RESUMEN}

Objetivo: Revisar un breve panel financiero, la normativa vigente y verificar los aspectos prácticos del reembolso al SUS. Métodos: Este fue un estudio cuantitativo y original para analizar el reembolso al SUS. La recolección de datos se llevó a cabo en la base de datos ANS y el repositorio académico de Google. Resultados: Según información de la ANS, en la evaluación de los últimos 5 años se traspasaron más de 3 mil millones, con una ganancia récord en 2019. Los servicios realizados entre los años 2015 y 2019 con mayores montos cobrados en el grupo de hospitalización son trasplantes de enfermedad renal, tratamientos de enfermedades bacterianas, tratamiento de múltiples cirugías, etc. En la atención ambulatoria de mediana

1 Universidade Federal do Estado do Rio de Janeiro (UNIRIO), Rio de Janeiro - RJ.

*E-mail: enfoadamcarlos@gmail.com

SUBMETIDO EM: 2/2021

ACEITO EM: 3/2021

PUBLICADO EM: 3/2021 
y alta complejidad destacan la hemodiálisis, hemodiálisis en un paciente con serología positiva para VIH y / o Hepatitis B y / o Hepatitis C etc. Las recomendaciones para la auditoría de registros médicos en unidades públicas por parte de los auditores de la OPS son importantes para la organización del proceso. Conclusión: Se encontró que el reembolso al SUS trajo cambios en el escenario de la atención de salud en el país, con un aumento en el reembolso de recursos y prácticas a mejorar.

Palabras clave: Reembolso al SUS, Salud complementaria, Sistema Único de Salud.

\section{INTRODUÇÃO}

O Sistema de Saúde no Brasil segundo Silva ACC, et al. (2020) é composto pelo Sistema Único de Saúde (SUS) em que os atendimentos são totalmente gratuitos e direcionados a toda a população, e o sistema de saúde suplementar, em que esse tipo de sistema é direcionado aos beneficiários que pagam por um tipo de atendimento ofertado por operadoras e seguradoras em saúde.

Conforme Dye C, et al. (2013) descreveu em seu estudo que todas as organizações, instituições e fundos formam o sistema que têm o objetivo de melhorar todos os níveis em saúde, em especial o primário. Diante disso, as operadoras em saúde estão inclusas neste sistema mesmo sendo suplementar. Para que esse sistema seja concretizado, são necessários alguns componentes como as equipes, os recursos, as informações, os fornecedores, o transporte e as comunicações, além de diretrizes de gestão integradas para que todo o sistema funcione.

Conforme a Constituição Federal (CF) em seu artigo 199, as instituições privadas poderão participar de forma complementar do SUS, mediante contrato de direito público ou convênio, tendo preferência às entidades filantrópicas e as sem fins lucrativos (BRASIL, 1988).

Segundo o instituto Brasileiro de Defesa do Consumidor (IDEC) (2006) o SUS é composto pelas três esferas de governo, sendo formado pela União, os Estados e os Municípios e de forma complementar pelo setor privado através de contratos e convênios de eventos em saúde. A partir desta contratualização, esses estabelecimentos conveniados entram na lógica do ressarcimento ao SUS.

A Saúde suplementar já diz respeito à classificação utilizada pelas seguradoras e operadoras de saúde que significa a escolha de o cidadão na contratação de um seguro privado para obter à assistência médica, além de manter a contribuição para a seguridade social, que inclui o direito ao acesso ao serviço público por meio de um sistema nacional de saúde como o SUS (BRASIL, 2011).

O cidadão tem por direito de utilizar ambos os sistemas de saúde, do atendimento prestado pelo SUS ou daquele disponibilizado por seguradoras e operadoras em saúde suplementar. Diante disso, não existe nenhuma ofensa à Constituição no fato de o paciente, à custa de recursos próprios, complementar com o serviço privado o atendimento prestado pelo SUS (BRASIL, 2010).

O beneficiário de planos de saúde que procuram os serviços do SUS normalmente tem como justificativa a negação da cobertura assistencial por algum motivo, ou por vontade própria do usuário. Quando o procedimento realizado possui cobertura contratual pelo plano, a operadora fica obrigada a ressarcir o SUS os valores gastos com o procedimento, sendo que, quando o procedimento não possui cobertura contratual pelo plano, não há cobrança de ressarcimento ao SUS (LIMA J, 2017).

Desta forma, conforme Brasil (1998), a Lei dos Planos de Saúde (№ 9.656) em seu artigo 32, todos os atendimentos serão ressarcidos pelas operadoras dos produtos de assistência à saúde, de acordo com normas a serem definidos pela Agência Nacional de Saúde (ANS), os serviços de atendimento à saúde prevista nos respectivos contratos, prestados aos seus consumidores e respectivos dependentes, em instituições públicas ou privadas, conveniadas ou contratadas, integrantes do Sistema Único de Saúde SUS. Reforça nessa questão, o reconhecimento da legalidade constitucional para o marco regulatório dos planos de saúde pelo STF, viabilizando a cobrança do ressarcimento ao SUS (BRASIL, 2018).

O Ressarcimento ao SUS é um repasse financeiro que as operadoras de planos e operadoras em saúde suplementar efetuam quando um de seus beneficiários realiza algum tipo de procedimento pelo SUS. Esta 
cobrança acontece após o cruzamento de dados do usuário através de $\mathrm{ABI}$ (Aviso de Beneficiário Identificado), a ANS envia para as Operadoras de Planos de Saúde especificando todos os dados do beneficiário, o tipo de atendimento e em qual unidade ele ocorreu (OLIVEIRA LA, 2018).

Segundo Rocha LSR (2018) na parte de procedimentos do ressarcimento ao SUS, a importância do cruzamento de dados é para excluir do rol de ressarcimento o atendimento de clientes que não tem plano de saúde ou que possuem contrato com plano de saúde, mas não estavam no Rol de cobertura do plano de saúde na época do atendimento.

Segundo Malta DC, et al. (2004) que descreveu em seu estudo sobre a regulação na saúde suplementar, são realizadas pela ANS através da aplicação dos modelos assistenciais e atua em três fases distintas como a capacidade financeira em honrar a prestação de serviço na assistência à saúde, a fiscalização das contratualizações efetuadas e a relação sobre o consumo e os produtos tanto na composição de cobertura contratual quanto no seu preço formado.

Conforme o Conselho Nacional de Saúde descreveu que o ressarcimento do SUS é mais do que um mecanismo de recuperação de recursos públicos e que o processo de análise dos dados do ressarcimento deve funcionar como informação estratégica para planejamento da expansão da rede assistencial em função das necessidades de saúde da população (BRASIL, 2018).

Através da sua Resolução Normativa (RN) No 358 , direciona todos os procedimentos administrativos físicos e híbridos de ressarcimento ao SUS, e estabelece normas sobre o repasse dos valores recolhidos a título de ressarcimento ao SUS. Com isso, essa RN em vigor normatiza a relação entre o ente público e o privado na assistência à saúde no país (BRASIL, 2014).

Diante do exposto, apresenta-se como objeto a análise do ressarcimento ao SUS no seu aspecto público e como os objetivos específicos verificar o breve painel financeiro, a norma vigente e verificar as questões práticas do ressarcimento ao SUS na assistência à saúde.

\section{MÉTODOS}

Tratou- se de um estudo do tipo quantitativo e original sobre os aspectos teóricos e práticos do ressarcimento ao SUS, abordando uma breve análise financeira, assistencial, operacional, com intuito de propor melhorias na qualidade da condução do processo de trabalho dos profissionais envolvidos.

O período do estudo foi analisado nos anos de repasse de 2015 até 2019 divulgados pela ANS. Utilizouse como critérios de inclusão todos os repasses de ressarcimento dos planos de saúde que utilizaram o SUS no período citado, os atendimentos realizados na assistência a saúde neste período em unidades públicas e/ou conveniadas e a avaliação dos Estados com maiores cobranças.

Como critérios de exclusão apresentaram-se indagar a legalidade do ressarcimento ao SUS, avaliar as impugnações realizadas pela ANS e a avaliação das operadoras em saúde suplementar envolvidas.

Por se tratar de um estudo com dados secundários, de domínio público e de estudos de gestão da qualidade e melhoria dos processos práticos envolvidos, não se disponibilizou de apreciação ética da avaliação de Comitê de Ética em Pesquisa (CEP).

A coleta de dados foi realizada através do reservatório da ANS para estruturar e dar embasamento ao que foi construído. As fontes documentais utilizadas para a construção do estudo foram obtidas por meio da busca de elementos normativos de base legal como legislações vigentes, Resoluções Normativas, Recomendações Institucionais, Trabalho de Conclusão de Curso, Dissertação de Mestrado e Artigos científicos sobre a temática disponibilizados no Google acadêmico. Utilizaram-se como palavras-chave para nortear o caminho de pesquisa o Ressarcimento ao SUS, Sistema Único de Saúde e Saúde Suplementar.

\section{RESULTADOS E DISCUSSÃO}

A Figura 1 abaixo descreve todo o processo a ser percorrido do ressarcimento ao Sistema Único de Saúde, constando desde o início do atendimento do beneficiário na rede pública ou conveniada de assistência à saúde até a dívida ativa em caso de não pagamento dos procedimentos realizados pela a Operadora de Saúde Suplementar. 
Figura 1 - Como funciona o ressarcimento ao SUS.

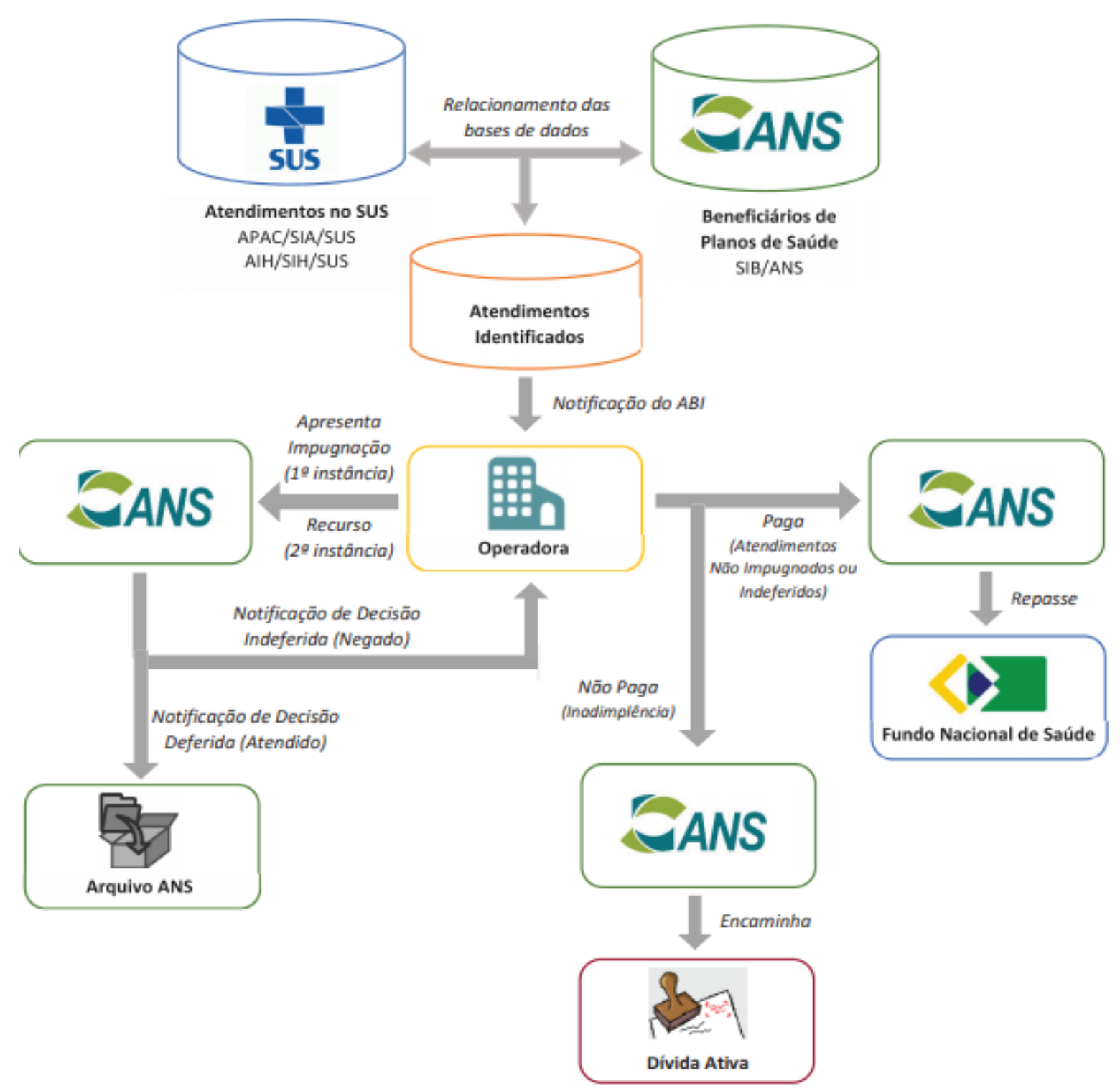

Fonte: Silva ACC, 2021; dados extraídos da Agência Nacional de Saúde Suplementar, 2018.

Todo esse processo tem início a partir do cruzamento dos dados inerentes aos atendimentos hospitalares e procedimentos executados no SUS com as informações do cadastro de portadores de planos de saúde que integram o banco de dados da ANS/MS (SECCHIN LBM, 2010).

Uma rotina de críticas no cadastro, os dados a filtros em que procuram descobrir os procedimentos sujeitos a cobrança de ressarcimento por parte das operadoras. Após identificar os procedimentos passíveis de cobrança, ofícios são enviados às operadoras denominados como Aviso de Beneficiário Identificado $(\mathrm{ABI})$. Após a sua notificação, as operadoras possuem um prazo, de 30 dias prorrogáveis por mais 30 dias, para realizar impugnações a essas cobranças, desde que tenha um caráter técnico ou administrativo (BRASIL, 2011).

Segundo informações, na avaliação dos últimos 5 anos mais de 3 bilhões, com um ganho recorde no ano de 2019. Desde o início do Ressarcimento ao SUS, a ANS cobrou das OPSs $R \$ 6,32$ bilhões, que equivalem a mais de 4,09 milhões de atendimentos realizados (BRASIL, 2020). Conforme o Gráfico 1 disponibiliza, segue os valores ressarcidos ao SUS ao FNS: 
Gráfico 1 - Valores ressarcidos ao SUS

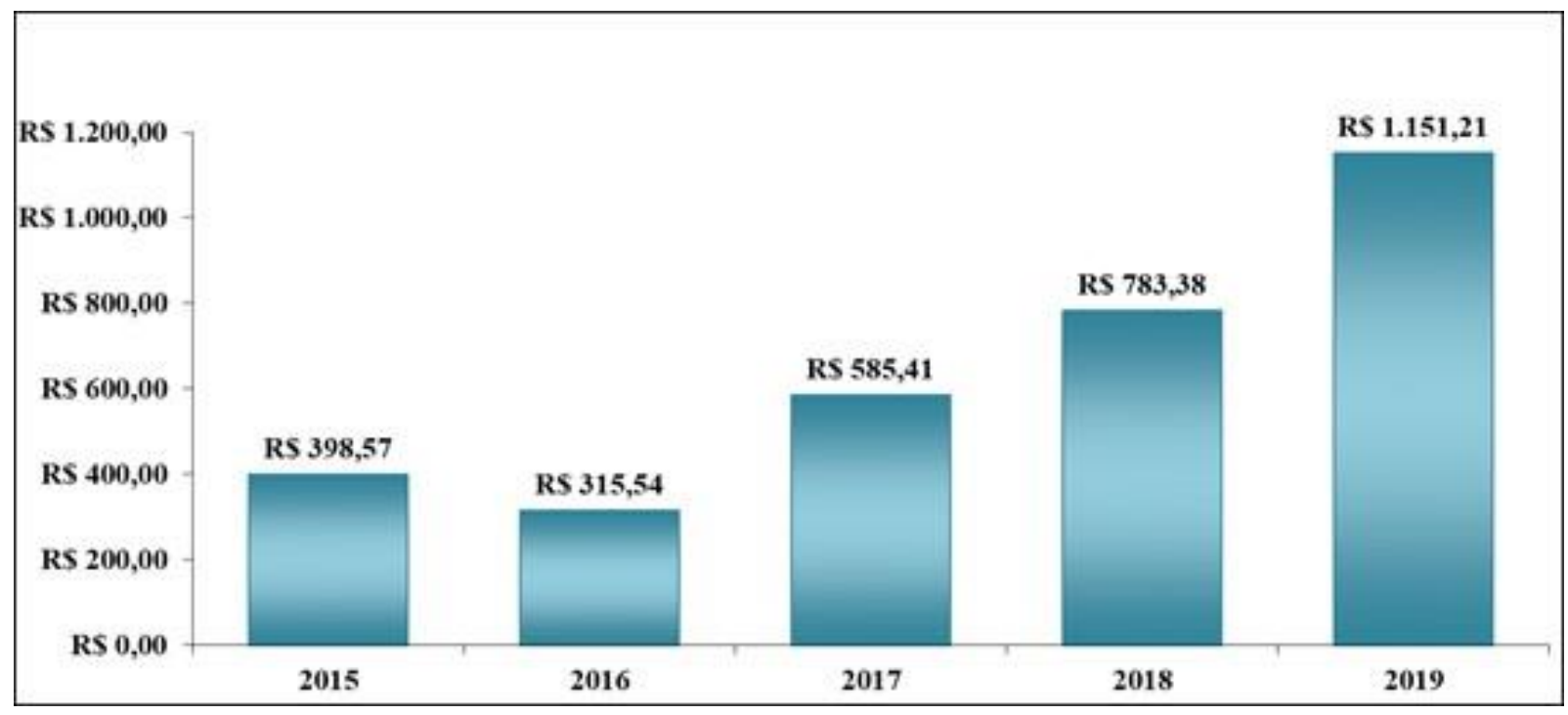

Fonte: Silva ACC, 2021; dados extraídos da Agência Nacional de Saúde Suplementar, 2020.

Os registros dos atendimentos para o ressarcimento ao SUS se dão através do atendimento gerado por Autorização de Internação Hospitalar $(\mathrm{AlH})$ e a Autorização de Procedimentos Ambulatoriais (APAC) (BRASIL, 2019).

A AlH é o documento com numeração própria em que se registra uma internação hospitalar realizada no SUS. Além de identificar o usuário que foi internado, a AlH indica, entre outros dados que os serviços prestados, a unidade de saúde, a competência (mês) do faturamento e o caráter da internação (BRASIL, 2019).

A APAC é o documento utilizado pelo SUS para autorizar a realização de procedimentos ambulatoriais de alta e de média complexidade e a disponibilização de medicamentos excepcionais. A APAC apresenta numeração própria e indica, entre outros, o nome, a data de nascimento e o sexo do usuário atendido, a unidade de saúde que prestou o atendimento, os procedimentos realizados e o caráter do atendimento. Ela indica as datas em que se iniciou e se encerrou o atendimento, indica o período em que o atendimento tem autorização para ser realizado (BRASIL, 2019).

O procedimento de identificação do beneficiário é realizado periodicamente pelo Departamento de Informática do SUS (DATA-SUS) que encaminha a ANS as bases das AlHs e APACs atendidas e pagas pelo SUS. A partir disso, a ANS realiza o chamado batimento, que é o cruzamento dos dados com o Sistema de Informação dos Beneficiários (SIB). Com isso, são identificados os beneficiários que possuem planos de saúde que foram atendidos e/ou internados no SUS em todas as suas complexidades. Após a realização do batimento, ocorrem filtros sobre estes atendimentos identificados para a exclusão por razões contratuais, evitando a cobrança (BRASIL, 2019).

Segundo o Instituto de Estudos em saúde Suplementar (IESS) (2020) em sua pesquisa da análise especial reflexões sobre a política de Ressarcimento ao SUS, a saúde suplementar apresenta uma produção assistencial superior ao que é solicitado para o ressarcimento. Mesmo considerando que na saúde suplementar são realizadas, em média, 7,8 milhões de internações por ano, verifica-se que a quantidade que poderá ser ressarcida ainda é relativamente baixa (cerca de $3,5 \%$ das internações da saúde suplementar).

As OPSs podem entrar com as impugnações ao ressarcimento, as operadoras podem argumentar a desobrigação de proceder ao pagamento por exemplo. Isto ocorre, pois existem eventos que ocorrem identificações de beneficiários que as operadoras não estão obrigadas a ressarcir o atendimento, em virtude de norma legal ou contratual como o Rol de coberturas, por exemplo (SCATENA MAN, 2004). 
Nesta perspectiva, estudo do IESS (2020) recomendou a oportunidade de aperfeiçoamento do processo de notificação pela a ANS, pois entre 2001 e 2017, a Agência concordou que $39 \%$ dos atendimentos de beneficiários pelo SUS impugnados haviam sido notificados equivocadamente e, portanto, os pleitos dos demandados foram deferidos.

Os valores recolhidos a título de ressarcimento ao SUS são integralmente revertidos ao Fundo Nacional de Saúde (FNS). Não havendo o pagamento, os valores são inscritos em dívida ativa da ANS, a quem compete à cobrança judicial dos respectivos créditos.

Os atendimentos realizados entre os anos de 2015 e 2019 com maiores valores cobrados no grupo de internações são os transplantes de rim (órgão de doador falecido), os tratamentos de doenças bacterianas, o tratamento de cirurgias múltiplas, o tratamento de pneumonias ou influenzas, o parto normal, os procedimentos sequenciais em oncologia, o transplante de rim (órgão de doador vivo), o parto cesariano, o tratamento de intercorrências após transplantes de órgãos (células- tronco hematopoéticas) e outros procedimentos com cirurgias sequenciais (BRASIL, 2020).

Pelos valores cobrados entre os atendimentos ambulatoriais de média e alta complexidade destacam-se a hemodiálise (máximo 3 sessões por semana), hemodiálise em paciente com sorologia positiva para o HIV e/ou Hepatite B e/ou Hepatite C (máximo 3 sessões por semana),a radioterapia com acelerador nuclear com fótons e elétrons (por campo), acompanhamento de pacientes pós-transplante de rim, fígado, coração, pulmão, células- tronco hematopoéticas e/ou pâncreas, hormonioterapia do adenocarcinoma de próstata avançado- primeira linha, manutenção e acompanhamento domiciliar de pacientes submetido à diálise peritoneal automatizada e diálise peritoneal ambulatorial contínua, quimioterapia de câncer na infância e na adolescência- primeira linha, quimioterapia do carcinoma de mama avançado- segunda linha, quimioterapia do carcinoma avançado mieloproliferativa para segunda linha e radioterapia com acelerador linear só de fótons (por campo) (BRASIL, 2020).

Diante dos inúmeros procedimentos realizados e identificados para a cobrança de valores a serem ressarcidos, reforça-se que, nem todos os procedimentos realizados no SUS por beneficiários de planos de saúde são cobrados às operadoras, pois são procedimentos que não constam no rol da ANS, ou não fazem parte do contrato aos quais os beneficiários estão vinculados, entre outros motivos, como a cobrança indevida. Nestes casos, as operadoras têm o direito de verificar a cobrança realizada em prontuário do paciente na unidade de originou a cobrança e solicitar a impugnação da cobrança quando considerar a mesma inadequada e a ANS irá julgar os recursos procedentes ou não. Após o término das análises e dos deferimentos e indeferimentos dos recursos, a ANS irá cobrar às operadoras os devidos custos referentes ao SUS (OLIVEIRA LA, 2018).

Estudo de Freitas MA (2011) sobre a avaliação da efetividade da política de ressarcimento ao sistema único de saúde, a tendência de se atingir o ressarcimento zero é quase nula, pois está ocorrendo o mecanismo contrário, diversas identificações estão sendo realizadas. Dentre os principais motivos para o fluxo de pacientes do setor privado para o setor público parecem ser a preferência dos beneficiários por serviços e ações do sistema público, em relação aos disponibilizados pelos seus próprios planos de saúde, e por algumas OPSs dificultarem ou limitarem o acesso de seus beneficiários à rede credenciada.

Os Estados que apresentaram maiores cobranças com Guia de Recolhimento da União (GRU) em ordem decrescente foram São Paulo, Minas Gerais, Rio de Janeiro, Paraná, Rio Grande do Sul, Santa Catarina, Pernambuco, Bahia, Ceará, Espírito Santo, Goiás, Distrito Federal, Pará, Rio Grande do Norte, Mato Grosso do Sul, Maranhão, Paraíba, Amazonas, Mato Grosso, Alagoas, Sergipe, Piauí, Rondônia, Tocantins, Acre, Amapá e Roraima conforme dados informativos (BRASIL, 2020).

A RN em vigor para o Ressarcimento ao SUS é a n 358 (2014) que dispõe sobre os procedimentos administrativos físico e híbrido de ressarcimento ao SUS, previsto no art. 32 da Lei $n^{\circ} 9.656$, de 3 de junho de 1998, e estabelece normas sobre o repasse dos valores recolhidos a título de ressarcimento ao SUS.

A partir do atendimento do paciente em qualquer unidade pública e conveniada, cabe a ANS a identificação e o procedimento administrativo, além de verificar a ocorrência da obrigatoriedade legal de 
ressarcir ao SUS por meio da constatação de atendimento no SUS ao beneficiário de plano privado de saúde e o cálculo do montante devido e da determinação da Operadora de Planos de Saúde (OPS) devedora (BRASIL, 2014).

A identificação é realizada mediante cruzamento de bancos de dados relativos aos atendimentos realizados nas unidades prestadoras de serviços vinculadas ao SUS com as informações cadastrais das OPSs constantes do banco de dados da ANS, nos termos do artigo 20 da Lei 9.656, de 3 de junho de 1998, e da regulamentação (BRASIL, 2014).

Os valores praticados para o ressarcimento ao SUS são calculados através do Índice de Valoração do Ressarcimento chamado de IVR, e as notificações e as intimações são feitas por meio eletrônico preferencialmente, porém ocorrendo dificuldade para a realização da intimação, poderá se utilizar os Correios com Aviso de Recebimento (BRASIL, 2014).

Para realizar a impugnação do pedido de ressarcimento ao SUS, a OPS terá o prazo de trinta dias após a identificação ser notificada. A impugnação deverá estar acompanhada das provas documentais das alegações, neste contexto, para a comprovação de motivos de natureza técnica, poderão auditar 0 prontuário dos atendimentos identificados, os profissionais de saúde das OPSs cadastrados perante a Secretaria de Atenção à Saúde do Ministério da Saúde - SAS-MS. Cabe apenas a "ANS" impugnar tais solicitações de impugnação (BRASIL, 2014).

Diante disso, a relação a ser desenvolvida entre Unidades públicas e/ou conveniadas e OPSs na comunicação da auditoria, prazo para a disponibilidade do prontuário do beneficiário, auditoria do prontuário e registro da auditoria realizada devem ser lembrados como parte do processo no ressarcimento ao SUS. Lembrando que apenas que a ANS pode impugnar qualquer tipo de solicitação de ressarcimento, cabendo apenas às unidades públicas e/ou conveniadas atenderem de forma organizada o processo de disponibilizar o prontuário do beneficiário. No Quadro 1 abaixo descrevem- se algumas sugestões para o relacionamento que demandam auditorias nos prontuários em unidade públicas ou conveniadas:

Quadro 1 - Recomendações para Auditorias de prontuários pelas OPSs em Unidades públicas e/ou conveniadas do SUS.

\begin{tabular}{|c|c|}
\hline AÇÕES & JUSTIFICATIVAS / RECOMENDAÇÕES \\
\hline $\begin{array}{c}\text { A OPS identificada deverá encaminhar a } \\
\text { comunicação de auditoria de prontuários } \\
\text { para a Unidade de origem, solicitando a } \\
\text { auditoria do prontuário do beneficiário } \\
\text { atendido pelo SUS com telefone de contato } \\
\text { e endereço eletrônico para retorno do } \\
\text { contato. }\end{array}$ & $\begin{array}{c}\text { As unidades públicas e/ou conveniadas direcionam as } \\
\text { solicitações das OPSs para o setor responsável } \\
\text { imediatamente, tendo em vista o prazo da OPS em } \\
\text { realizar a verificação do prontuário em caso de pedido de } \\
\text { impugnação. Evitar alegações das OPSs quanto à } \\
\text { negativa de acesso a verificação de prontuários. }\end{array}$ \\
\hline $\begin{array}{c}\text { Após o contato com a unidade pública, o } \\
\text { setor responsável providencia o prontuário a } \\
\text { ser auditado pelo o profissional da OPS } \\
\text { devidamente cadastrado via MS. }\end{array}$ & $\begin{array}{c}\text { Neste processo, o mais ideal que seja o setor de auditoria } \\
\text { ou na sua ausência, o setor de faturamento da unidade. } \\
\text { Recomenda-se um prazo mais breve possível após a } \\
\text { comunicação, para a disponibilidade do prontuário do } \\
\text { paciente para realizar a auditoria pelo profissional da } \\
\text { OPS. }\end{array}$ \\
\hline $\begin{array}{c}\text { O Auditor da OPS cadastrado na Secretaria } \\
\text { de Atenção à Saúde- MS audita o prontuário } \\
\text { do beneficiário identificado conforme ANS } \\
\text { (2014). }\end{array}$ & $\begin{array}{c}\text { Recomendam-se as unidades públicas e conveniadas a } \\
\text { verificarem o cadastro dos auditores conforme Portarias } \\
\text { do Ministério da Saúde.Além disso, que tenha um } \\
\text { profissional de nível superior em saúde da unidade para } \\
\text { acompanhar o auditor da OPS durante o processo de } \\
\text { auditagem para sanar possíveis dúvidas. }\end{array}$ \\
\hline $\begin{array}{c}\text { Depois de terminada a auditoria do } \\
\text { prontuário, recomenda-se que seja } \\
\text { registrada a visita do auditor da OPS pelo } \\
\text { profissional da unidade pública ou } \\
\text { conveniada em livro de registro ou protocolo } \\
\text { definido. }\end{array}$ & $\begin{array}{c}\text { Recomenda-se esse procedimento para registrar a } \\
\text { liberação da solicitação realizada pela OPS, conforme } \\
\text { determinação da ANS e a informação de acesso ao } \\
\text { prontuário do beneficiário. }\end{array}$ \\
\cline { 2 - 2 }
\end{tabular}

Fonte: Silva ACC, 2020. 
De acordo com o Quadro 1, vale ressaltar que são apenas sugestões e recomendações conforme experiência prévia, sem nenhuma obrigação aos órgãos envolvidos. Cabe apenas a ANS via MS regulamentar qualquer tipo de procedimento a ser seguido pelas OPSs e as unidades públicas e/ou conveniadas. Porém, sabe-se da preocupação das Unidades públicas e/ou conveniadas com o SUS em direcionar todo o processo, e como a temática relativamente nova Resolução Normativa №358 de 2014, ocorre o desconhecimento de muitos profissionais da rede pública, quanto ao acesso aos prontuários pelos Auditores da OPS e ao processo regulamentado pela ANS.

Vale reforçar, que área da saúde, a auditoria é conceituada como exames sistemáticos e independentes dos fatos que são realizados por observação, medição, ensaio de uma atividade, elemento ou sistema, verificando a adequação aos requisitos preconizados pelas leis e normas legais, determinando se as ações de saúde e seus resultados estão de acordo com as disposições planejadas (AYACH C et al, 2013).

Neste contexto, cabe a auditoria buscar sempre agilidade de intervenção no processo, a identificação de prioridades e a organização de sistema de saúde. Além de indicar os problemas e as falhas através de seus relatórios, também aponta as sugestões e soluções, assumindo um caráter educativo na construção do cuidado (AYACH C, et al., 2013).

Após a decisão da constitucionalidade da legislação do ressarcimento ao SUS desde 2018, cada dia mais solicitações poderão ser realizadas, visto o crescimento do ressarcimento nos anos analisados e o aumento considerável em 2019. Devido a isso, recomenda-se a organização das OPSs e por parte das unidades públicas e/ou conveniadas deste processo, lembrando que tanto para o SUS quanto para a saúde suplementar, este processo gera desafios para ambas as partes, e estruturá-lo é a melhor forma de atender as legislações e regulamentações vigentes em prol dos usuários e a organização do sistema de saúde.

\section{CONCLUSÃO}

De acordo com os dados apresentados, verificou-se que o ressarcimento ao SUS trouxe mudanças no cenário da assistência à saúde no país, com o aumento no ressarcimento de recursos e práticas para serem aperfeiçoadas no cotidiano. Em especial no cenário das unidades públicas e/ou conveniadas, recomenda-se a verificação das normas da ANS e o reforço na orientação da Resolução Normativa em vigor na questão da prática da auditoria em saúde, para que essas instituições, junto aos profissionais estejam preparadas para essa modalidade no sistema de saúde.

\section{REFERÊNCIAS}

1. AYACH C, et al. Auditoria no Sistema Único de Saúde: o papel do auditor no serviço odontológico. Saúde soc. vol.22 no. 1 São Paulo Jan./Mar. 2013.

2. BRASIL. AGÉNCIA NACIONAL DE SAÚDE SUPLEMENTAR (ANS). Utilização do Sistema Único de Saúde por Beneficiários de Planos de Saúde e Ressarcimento ao SUS. Décima edição, Rio de Janeiro, Jun/2020.

3. BRASIL. AGÊNCIA NACIONAL DE SAÚDE SUPLEMENTAR (ANS). Ressarcimento: ANS disponibiliza nova edição do Mapa de Utilização do SUS. Integração com o SUS, Rio de Janeiro, Ago/2020.

4. BRASIL. Agência Nacional de Saúde Suplementar (ANS). Resolução Normativa- RN n 358 de 27 de novembro de 2014. Agência Nacional de Saúde Suplementar. - Rio de Janeiro: ANS, 2014.

5. BRASIL. Agência Nacional de Saúde Suplementar (ANS). (Guia do Ressarcimento ao SUS: Impugnações e recursos. Rio de Janeiro, 2019.

6. BRASIL. Agência Nacional de Saúde Suplementar (ANS). Boletim informativo: Utilização do sistema público por beneficiários de planos de saúde e ressarcimento ao SUS. Rio de Janeiro: ANS, 2018

7. BRASIL. Conselho Nacional de Saúde (CNS). Recomendação Nº43, de 11 de Outubro de 2018. Trecentésima Décima Reunião, Out/ 2018.

8. BRASIL. Conselho Nacional de Secretários de Saúde (CONASS). Saúde Suplementar. Para Entender a Gestão do SUS. 12) SUS (BR). 2. 148 p., - Brasília: 2011.

9. BRASIL. Supremo Tribunal Federal (STF). Recurso extraordinário 516.67 Rio Grande do Sul. Primeira Turma. Brasília, Out/ 2010. BRASIL. Lei de no 9.656, de 03 de Junho de 1998, Diário Oficial [da] República Federativa do Brasil, Brasília, DF, Dispõe sobre os planos e seguros privados de assistência à saúde.

10. BRASIL. Constituição da República Federativa do Brasil de 1988. Diário Oficial [da] República Federativa do Brasil, Brasília, DF, cinco out. 1988.

11. DYE C, et al. Research for universal health coverage. Sci Transl Med 2013; 5(199). 
12. FREITAS MA. A avaliação da efetividade da política de ressarcimento ao Sistema Único de Saúde. Dissertação Mest - Escola de Administração de Empresas de São Paulo. FGV, São Paulo, 2011.

13. INSTITUTO BRASILEIRO DE DEFESA DO CONSUMIDOR. IDEC. O SUS pode ser o seu melhor plano de saúde. Terceira edição, São Paulo, 2006.

14. INSTITUTO DE ESTUDOS EM SAÚDE SUPLEMENTAR. IESS. Análise especial, reflexões sobre a política de Ressarcimento ao SUS. Nota detalhada, Dez/2020.

15. LIMA JÚNIOR, AA. Aspectos jurídico-constitucionais e práticos do ressarcimento ao Sistema Único de Saúde. Trabalho de Conclusão de Curso (Graduação). Fortaleza: Universidade Federal do Ceará. Faculdade de Direito, 2017.

16. MALTA DC, et al. Perspectivas da regulação na saúde suplementar diante dos modelos assistenciais. Scielo Scientific Electronic Library Online, 2004.

17. OLIVEIRA LA. Ressarcimento ao SUS e os custos assistenciais das operadoras de planos de saúde no Brasil, 2006 a 2016. Curso de Ciências Atuarias, UFRN, Natal- RN, 2018. 54f.: il.

18. ROCHA SRL. Ressarcimento ao SUS: Entre princípios, propósitos e procedimentos. Trabalho de Conclusão de Curso (Graduação), Brasília. Universidade de Brasília, Faculdade de Economia, Administração, Contabilidade e Gestão de Políticas Públicas, 2018.

19. SCATENA MAN. O Ressarcimento ao SUS: Análise do perfil de utilização do Sistema Único de Saúde segundo período da contratação dos planos. Dissert. Mest., Escola Nacional de Saúde Pública Sérgio Arouca - ENSP, FIOCRUZ, 2004.

20. SECCHIN LBM. Ressarcimento ao SUS e os Principais Conceitos. Rio de Janeiro: [s.n.], set. 2010.

21. SILVA ACC, et al. Sistema de acreditação nas operadoras de saúde suplementar: análise e perspectivas de mercado. Revista Eletrônica Acervo Saúde, 12(11), e4022. 